G. Liccardi ${ }^{1-2}$, L. Calzetta ${ }^{2-3}$, G. Apicella ${ }^{1}$, G. Baldi ${ }^{4}$, A. Berra ${ }^{5}$, F. Califano ${ }^{6}$, A. Ciccarelli ${ }^{7}$, M. Cutajar ${ }^{8}$, M. D’Amato 9 , G. De Crescenzo $^{10}$, E. Di Maro ${ }^{1}$, D. Gargano ${ }^{11}$, D. GiannatTasio ${ }^{12}$, G. Inciso ${ }^{13}$, M. Lo Schiavo ${ }^{6}$, F. Madonna ${ }^{14}$, M. Maniscalco ${ }^{15}$, C. Montera ${ }^{6}$, G. Papa ${ }^{16}$, A. Pedicini ${ }^{17}$, R. Pio ${ }^{6}$, A. Salzillo ${ }^{1}$, A. Stanziola 9 , P. Rogliani ${ }^{2-3}$, A. Musarra ${ }^{18}$

\title{
Allergy in adolescent population (14-18 years) living in Campania region (southern Italy). A multicenter study
}

${ }^{1}$ Department of Pulmonology, Haematology and Oncology, Division of Pulmonology and Allergology. High Speciality A. Cardarelli Hospital, Naples, Italy

${ }^{2}$ Postgraduate School of Respiratory Medicine. Department of Experimental Medicine, University of Rome Tor Vergata, Rome, Italy

${ }^{3}$ Department of Experimental Medicine, University of Rome Tor Vergata, Rome,

${ }^{4}$ Respiratory Medicine Unit, ASL (District 66), Salerno, Italy

${ }^{5}$ Respiratory Allergy Unit. G. Da Procida Hospital, Salerno, Italy

${ }^{6}$ Allergy and Clinical Immunology, G. Fucito Hospital and University Hospital, Salerno, Italy

${ }^{7}$ Allergy Unit, Presidio Sanitario Polispecialistico Loreto Crispi Naples, Italy

${ }^{8}$ Allergy Center, Division of Internal Medicine, Ospedali Riuniti Penisola Sorrentina, Sorrento (NA), Italy

${ }^{9}$ Department of Respiratory Disease, Federico II University, AO Dei Colli, Naples, Italy

${ }^{10}$ Allergy and Clinical Immunology Unit, High Speciality Sant'Anna and San Sebastiano Hospital, Caserta, Italy

${ }^{11}$ Allergy Unit, High Speciality San Giuseppe Moscati Hospital, Avellino, Italy

${ }^{12}$ Respiratory Physiopathology and Allergy, High Speciality Center Mauro Scarlato Hospital, Scafati (SA), Italy

${ }^{13}$ Allergy Unit, ASL Na 3 (Sanitary District 59), Meta di Sorrento (NA), Italy

${ }^{14}$ Allergy Unit, ASL (Sanitary District 12), Caserta, Italy

${ }^{15}$ Pulmonary Rehabilitation Unit ICS Maugeri, Telese Terme, Benevento, Italy

${ }^{16} \mathrm{ASL}$ (Sanitary District), Avellino, Italy

${ }^{17}$ Allergology Unit, Division of Internal Medicine, Fatebenefratelli Hospital, Benevento, Italy

${ }^{18}$ Allergy Unit, National Healthcare System, Reggio Calabria, Italy

Promoted by Italian Association of Hospital and Territorial Allergologists (AAIITO, Campania Region). Data presented in Poster Session at National Congress of AAIITO, Palermo 11-14 October 2017

\section{KEY WORDS}

adolescents; allergy; allergic rhinitis; allergic sensitization; bronchial asthma; Campania region; elderly; hypersensitivity

\author{
Corresponding author \\ Gennaro Liccardi \\ Department of Pulmonology, \\ Haematology and Oncology \\ Division of Pneumology and Allergology \\ High Speciality A. Cardarelli Hospital \\ Piazzetta Arenella 7, 80128 Naples, Italy \\ Phone: +39 081747 3335-4-3 \\ Fax: + 390817473331 \\ E-mail: gennaro.liccardi@tin.it
}

Doi

10.23822/EurAnnACI.1764-1489.65 


\section{Summary}

Adolescents $(A d)$ constitute a difficult to manage population among individuals suffering from asthma. The aim of our study was to assess the prevalence, clinical characteristics and age of onset of allergic sensitization and clinical symptoms in a sample of atopic Ad living in the Campania region (Southern Italy). Sixteen Allergy units or Centers belonging to the Italian Association of Hospital and Territorial Allergologists (AAIITO, Campania region) participated in this cross-sectional study. A case report form (CRF) was specifically designed for this study and commercial allergen extracts used for screening SPTs were provided by ALK-Abelló Group (Milan, Italy). A total of 443 patients were examined (females, F 220, 49.6\%; males, M 223, 50.3\%). Dust mites represent the most common sensitizing agents in allergic Ad living in Campania region (Dermatoph. pteronyssinus 67.4\% and Dermatoph. farinae 66.5\%), followed by Parietaria (58.9\%), grasses (45.8\%), Artemisia vulgaris (16.7\%), Olea Europaea (32.2\%), dog dander (17.1\%), cat dander (20.0\%), Alternaria alternata (8.1\%), Cupressus sempervirens (4.9\%), Betula pendula (4.7\%), other allergens (19.4\%). An interesting comparison has been made between clinical data of our Ad with data of elderly patients (E). The role of allergic sensitization is significantly higher in Ad compared to E. Dermatophagoides pteronyssinus is the first sensitizing allergen in Ad and the last in E. Parietaria constitutes the first sensitizing pollen both in Ad and E, the percentage of sensitization is higher in Ad. Another important difference is the higher prevalence of asthma (As), as only symptom, in E compared to Ad (19.7\% versus $7.6 \%)$.

In conclusion, our findings confirm the high prevalence and clinical significance of airway allergic sensitization in the adolescents living in Campania region.

\section{To the Editor}

It is widely recognized that Ad constitute a difficult to manage population among individuals suffering from asthma. In fact, asthmatic Ad may experience a period of physical and psychosocial changes that affect their health and well-being. Overall, Ad with asthma are at increased risk for asthma morbidity and death. Increased rates of depression and anxiety, for the Ad and their caregivers, can lead to non-adherence to their medical regimens, poor symptom control and poor treatment outcomes (1). Contextual factors, such as race, ethnicity, and personal characteristics (particularly cigarette smoke or the use of narcotics), affect the prevalence, morbidity, and mortality for the Ad with asthma. These factors also affect the transition process for Ad entering adult medical care (2). As a consequence of these factors, asthma during adolescence impairs health-related quality of life, especially if the asthma is uncontrolled (3). Based on this background, the aim of our study was to assess the prevalence, clinical characteristics and age of onset of allergic sensitization and clinical symptoms in a sample of atopic Ad living in Campania region (southern Italy). Sixteen Allergy units or Centres belonging to the Italian Association of Hospital and Territorial Allergologists (AAIITO, Campania region), uniformly distributed over the whole territory of Campania region $\left(13,595 \mathrm{Km}^{2}, 5,833,332\right.$ inhabitants at 30 November 2014) participated in this cross-sectional study. The same protocol was shared by all participating centers; each centre collected the results of allergy consultations of consecutive outpatients, aged $14-18$ years, referred for suspected or current respiratory allergy (asthma and/or rhinitis). Patient enrollment started on January 1 and ended on June 30, 2017.
A case report form (CRF) specifically designed for this study was completed during the screening consultation of each patient. The standardized form reported: demographic data, type and duration of respiratory symptoms, pet ownership, results of skin prick tests (SPTs), age of onset of respiratory symptoms. The diagnosis of respiratory allergy has been carried out according to the International Guidelines $(4,5)$.

The commercial allergen extracts used for screening SPTs were provided by ALK-Abellò Group (Milan, Italy). A standard panel of allergens was used, including Dermatophagoides pteronyssinus and Dermatophagoides farinae, Alternaria alternata, Cladosporium herbarum, cat and dog dander, Parietaria, grass pollen mix, Artemisia vulgaris, Olea europaea, Betula pendula, Cupressus sempervirens and Corylus avellana. This allergen panel covers the main causative agents of respiratory allergy in Campania region. Positive $(10 \mathrm{mg} / \mathrm{ml}$ histamine $\mathrm{HCl})$ and negative (saline solution in glycerine-phenol solution) controls were used. SPTs were performed and interpreted according to International Guidelines (6); results were read after 15 minutes and expressed as the mean of the major wheal diameter plus its orthogonal. A skin reaction of $3 \mathrm{~mm}$ or greater was considered positive. Wheal profiles were outlined using a fine-point marking pen and transferred by adhesive tape onto the patient's case report form.

Patients with chronic or dysmetabolic diseases, severe cutaneous disorders, negative skin reaction to histamine, or undergoing treatment with drugs interfering with skin response were excluded from the study $(7,8)$.

A total of 443 patients were examined (females, F 220, 49.6\%; males, M 223, 50.3\%). Three hundred and fifty subjects (76.7\%) had positive SPTs to at least one allergen and were diagnosed with respiratory allergy, the remaining 103 (23.2\%) were SPTs-negative. The prevalence of allergic sensitization 
Figure 1 - Prevalence of allergic sensitization to perennial/seasonal allergens in adolescents living in Campania region.

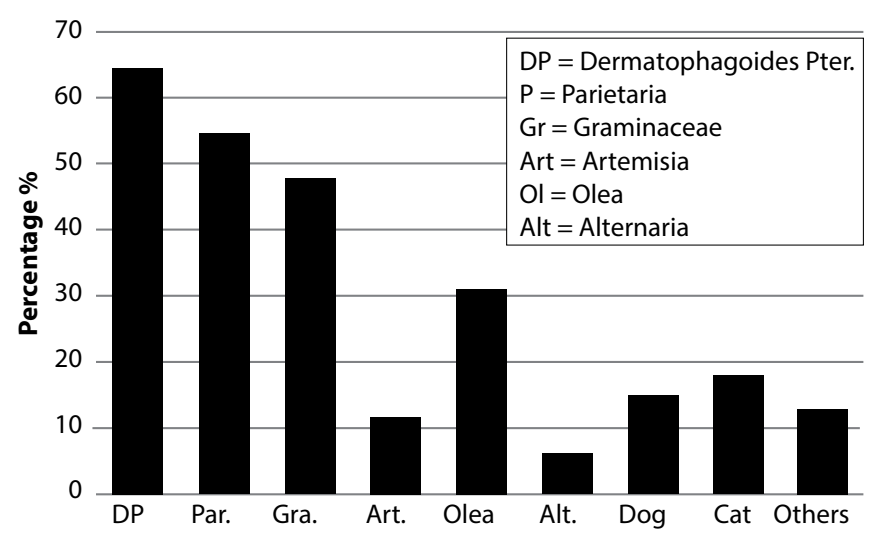

was almost identical in both sexes $(50.3 \% \mathrm{M}$ and $49.6 \% \mathrm{~F})$. Dust mites represent the most common sensitizing agents in allergic adolescents living in Campania region (Dermatoph. pteronyssinus $67.4 \%$ and Dermatoph. farinae 66.5\%), followed by Parietaria (58.9\%), grasses (45.8\%), Artemisia vulgaris $(16.7 \%)$, Olea europaea (32.2\%), dog dander (17.1\%), cat dander (20.0\%), Alternaria alternata (8.1\%), Cupressus sempervirens $(4.9 \%)$, Betula pendula $(4.7 \%)$, other allergens (19.4\%) (figure 1).

These data are in agreement with previous reports on children and adults living in Campania region and Naples area, where the most common sensitizing agents were dust mites followed by Parietaria, Grass pollen and Olea europaea $(9,10)$. Most of our Ad shows a poly in comparison to mono pattern of allergic sensitization, and this finding is confirmed also by other authors $(11,12)$. As regards clinical symptoms, $64.5 \%$ of our patients reported exclusively rhinitis (R), 7.6\% only asthma (As), 32.2\% $\mathrm{R}+$ As, and finally $55.3 \%$ conjunctivitis. Nasal symptoms are present in the totality (100\%), whereas bronchial symptoms in $40.7 \%$ of our adolescents.

The age of onset of clinical symptoms in our patients is shown in figure 2. An interesting comparison can be made between $\mathrm{Ad}$ and $\mathrm{E}$ patients living in Campania region, because data are comparable being produced by the same working group (figure 3 ). The number of patients is comparable in both ages (443 Ad and $462 \mathrm{E}$ ), sex rate is similar in $\mathrm{Ad}$ ( $\mathrm{F} 49.6 \%, \mathrm{M} 50.3 \%$ ), a significant prevalence of $\mathrm{F}$ can be observed in $\mathrm{E}$ (F $62.9 \%$, M 37.0\%). In fact, adolescence is the age of change in the prevalence of respiratory allergy, which is higher in $\mathrm{M}$ during paediatric age and in F during adulthood. A positive SPT for at least one allergen was found in $76.7 \%$ of $A$ and in $46.5 \%$ of $\mathrm{E}$. The prevalence of allergic sensitization was almost identical in both sexes in Ad (M 50.1\%
Figure 2 - Age of onset of respiratory symptoms in enrolled adolescents living in Campania region.

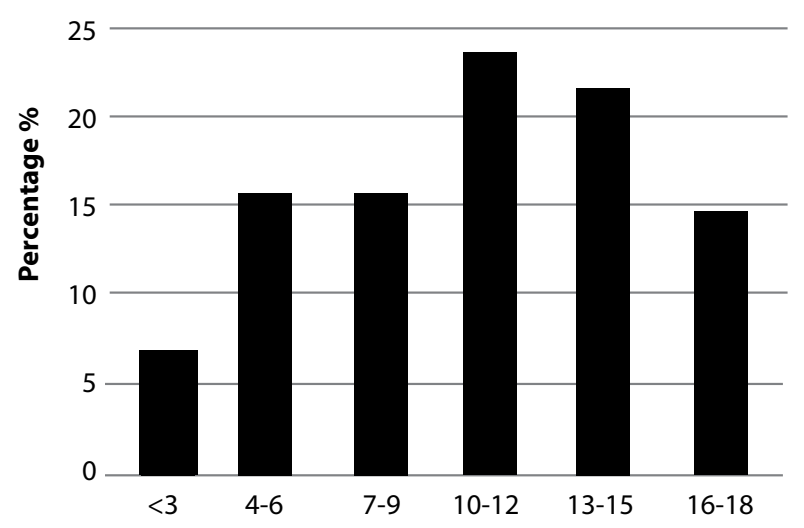

and $\mathrm{F}$ 49.9\%), whereas female sex is prevalent, as expected, in $\mathrm{E}$ (F 60.7\%, M 39.3\%). Dust mites constitute the most frequent sensitizing agent in $\mathrm{Ad}$, whereas pollens are involved in respiratory allergy in $\mathrm{E}$. In order of frequency, $\mathrm{R}, \mathrm{R}+\mathrm{As}$ and As represent the most common clinical symptoms both in $\mathrm{Ad}$ and in $\mathrm{E}$.

Figure 3 clearly shows that the role of allergic sensitization to the four most common allergens in Campania region is significantly higher in Ad compared to E. In particular, Dermatophagoides pteronyssinus is the first sensitizing allergen in Ad and the last in $\mathrm{E}$ according to its early contact with airways. Parietaria constitutes the first sensitizing pollen both in $\mathrm{Ad}$ and $\mathrm{E}$, the percentage of sensitization is higher in Ad. Another important difference showed by figure 3 is the higher prevalence of As, as only symptom, in E compared to Ad (19.7\% versus 7.6\%). The higher prevalence of As in $\mathrm{E}$ is likely the consequence of a longer exposure to environmental or professional risk factors.

In conclusion, our data show that the prevalence and clinical importance of airway allergic sensitization in the Ad living in Campania region is very relevant. Our findings confirm that allergic sensitization in adolescence constitutes a turning point between the peculiar characteristics of the child and those of the adult. Present data on Ad integrate our knowledge on allergic population living in Campania region derived from previous studies (13-15).

\section{Acknowledgements}

We thank Gaetano Francesco Salzillo and Romina D’Angelo for their kind technical assistance in the preparation of figures.

\section{Conflict of interest and financial resources}

All authors declare that they have no conflict of interest. 
Figure 3 - Comparative data of adolescent and elderly patients living in Campania region and suffering from suspected allergic airway diseases.

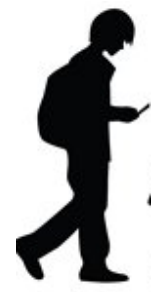

443

F 220,49.6\%; M 223, 50.3\%

$76.7 \%$

M 50.1\%, F 49.9\%

DP $67.4 \%$, P 58.9\%, Grasses $45.8 \%$, Ol.e $32.2 \%$

$R$ 64.5\%, A 7.6\%, R + A 32.3\%, C 55.3\%

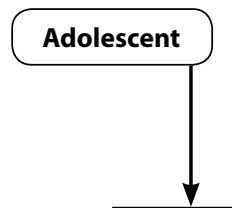

$N^{\circ}$ of patients

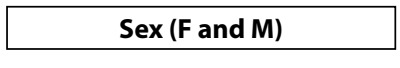

Positive SPT percentage

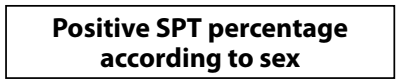

The most common sensitizing allergens

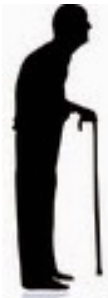

462

F 291, 62.9\%; M 171, 37.0\%

$46.5 \%$

M 39.3\%, F 60.7\%

P 46.5\%, Grasses 24.7\%, DP $23.7 \%$, Ol.e $13.5 \%$

Clinical symptoms

$\mathrm{F}=$ female; $\mathrm{M}=$ male; $\mathrm{DP}=$ Dermatophagoides pteronyssinus $\mathrm{P}=$ Parietaria; Ol. $\mathrm{e}=$ Olea europaea; $\mathrm{R}=$ Rhinitis; $\mathrm{A}=\mathrm{Asthma}$; $\mathrm{C}=\mathrm{Conjuctivitis;} \mathrm{SPT}=$ Skin Prick Test. 'Liccardi G. et al., Eur Ann Allergy Clin Immunol 2016; 48: 156-160 (15).

\section{References}

1. Bitsko MJ, Everhart RS, Rubin BK. The adolescent with asthma. Paediatr Respir Rev 2014; 15:146-153.

2. Fleming L, Murray C, Bansal AT, Hashimoto S, Bisgaard H, Bush A. The burden of severe asthma in childhood and adolescence: results from the paediatric U-BIOPRED cohorts. Eur Respir J 2015; 46:1322-1333.

3. Jonsson M, Bergstrom A, Egmar AC, Hedlin G, Lind T, Kull I. Asthma during adolescence impairs health-related quality of life. J Allergy Clin Immunol Pract 2016; 4:144-146.

4. Bousquet J and the ARIA Workshop Group. Allergic rhinitis and its impact on asthma. J Allergy Clin Immunol 2001; 108:S147-S336.

5. Global Initiative for Asthma.http://ginasthma.com

6. Bousquet J, Heinzerling L, Bachert C, Papadopoulos NG, Bousquet PJ, Burney PG et al. Global Allergy and Asthma European Network; Allergic Rhinitis and its Impact on Asthma. Practical guide to skin prick tests in allergy to aeroallergens. Allergy 2012; 67:18-24.

7. Bousquet J, Michel FB. Precision of prick and puncture tests. J Allergy Clin Immunol 1992; 90:870-872.

8. Wever AMJ, Wever-Hess J. Testing for inhalant allergy in asthma. Clin Exp Allergy 1993; 23:976-981.

9. Liccardi G, Visone A, Russo M, Saggese M, D'Amato M, D’Amato G: Parietaria pollinosis: clinical and epidemiological aspects. Allergy Asthma Proc 1996; 17:23-29.

10. Liccardi G, Russo M, Piccolo A, Lobefalo G, Salzillo A, D’Amato M, D'Amato G: The perennial pattern of clinical symptoms in children monosensitized to Olea europaea pollen allergens in comparison with subjects with Parietaria and Gramineae pollinosis. Allergy Asthma Proc 1997; 18:99-105.
11. Anto JM, Bousquet J, Adkis M, Auffray C, Keil T, Momas I et al. Mechanisms of the development of allergy (MeDALL): Introducing novel concepts in allergy phenotypes. J Allergy Clin Immunol 2017; 139:388-399.

12. Schou Nielsen J, Meteran H, Ulrik CS, Porsbjerg C, Backer V. Natural history of skin prick test reactivity: A 20-year prospective study of a random population sample of children and adolescents. Ann Allergy Asthma Immunol. 2017; 119: 184-188.

13. Liccardi G, Baldi G, Ciccarelli A, Cutajar M, D’Amato M, Gargano D, Giannattasio D, Leone G, Lo Schiavo M, Madonna F, Montera C, Pio A, Russo M, Salzillo A, Stanziola A, D'Amato G. On behalf of Italian Association of Hospital and Territorial Allergologists (AAITO, Campania District, Southern Italy). Sensitization to rodents (mouse/rat) in urban atopic populations without occupational exposure living in Campania District (Southern Italy). A multicenter study. Multidiscip Respir Med 2013; 8:30.

14. Liccardi G, Baldi G, Ciccarelli A, Cutajar M, D’Amato M, Gargano D , Giannattasio D, Leone G, Lo Schiavo M, Madonna F, Montera C, Piccolo A, Pio A, Russo M, Stanziola A, D'Amato G. On behalf of Italian Association of Hospital and Territorial Allergologists (AAITO - Campania District, Southern Italy). Sensitization to cockroach allergens in the urban atopic populations living in Campania district (southern Italy). A multicenter study. Eur Ann Allergy Clin Immunol 2014; 46: 12-16.

15. Liccardi G, Baldi G, Berra A, Ciccarelli A, Cutajar M, D’Amato $\mathrm{M}$ et al. Italian Association of Hospital and Territorial Allergologists (AAIITO, Campania region). Allergy in urban elderly population living in Campania region (Southern Italy). A multicenter study. Eur Ann Allergy Clin Immunol 2016; 48:156-160. 